\title{
Formulating policy activities to promote healthy and sustainable diets
}

\author{
Mark A Lawrence ${ }^{1, *}$, Sharon Friel ${ }^{2}$, Kate Wingrove ${ }^{1}$, Sarah W James $^{2}$ and Seona Candy ${ }^{3}$ \\ ${ }^{1}$ School of Exercise and Nutrition Sciences, Deakin University, 221 Burwood Highway, Burwood, VIC 3125, \\ Australia: ${ }^{2}$ Regulatory Institutions Network, The Australian National University, Canberra, ACT, Australia: ${ }^{3}$ Victorian \\ Eco-Innovation Lab, University of Melbourne, Carlton, VIC, Australia
}

Submitted 7 November 2014: Final revision received 17 July 2015: Accepted 23 July 2015: First published online 18 August 2015

\begin{abstract}
Objective: To develop a policy formulation tool for strategically informing food and nutrition policy activities to promote healthy and sustainable diets (HSD).

Design: A policy formulation tool consisting of two complementary components was developed. First, a conceptual framework of the environment-public health nutrition relationship was constructed to characterise and conceptualise the food system problem. Second, an 'Orders of Food Systems Change' schema drawing on systems dynamics thinking was developed to identify, assess and propose policy options to redesign food systems.

Setting: Food and nutrition policy activities to promote HSD have been politicised, fragmented and lacking a coherent conceptual and strategic focus to tackle complex food system challenges.

Results: The tool's conceptual framework component comprises three integrated dimensions: (i) a structure built around the environment and public health nutrition relationship that is mediated via the food system; (ii) internal mechanisms that operate through system dynamics; and (iii) external interactions that frame its nature and a scope within ecological parameters. The accompanying schema is structured around three orders of change distinguished by contrasting ideological perspectives on the type and extent of change needed to 'solve' the HSD problem. Conclusions: The conceptual framework's systems analysis of the environmentpublic health nutrition relationship sets out the food system challenges for HSD. The schema helps account for political realities in policy making and is a key link to operationalise the framework's concepts to actions aimed at redesigning food systems. In combination they provide a policy formulation tool to strategically inform policy activities to redesign food systems and promote HSD.
\end{abstract}

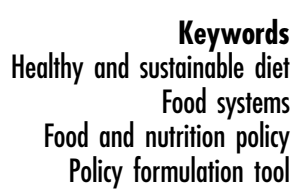

The policy challenges arising from public health nutrition (PHN) and environmental sustainability problems are unprecedented. Dietary behaviours contribute to 1.4 billion people globally being overweight and obese ${ }^{(1)}$ and are implicated in fourteen of the top twenty determinants of global deaths ${ }^{(2)}$. Along with an increasing population size, dietary behaviours also place significant demands on the environment to provide a sufficient food supply. Relatedly, diminishing environmental resources ${ }^{(3)}$ and climate change threaten global food and nutrition security ${ }^{(4)}$ with reportedly 868 million people currently undernourished ${ }^{(5)}$.

These PHN and environmental sustainability problems are interconnected and share common dietary causes and solutions - a healthy diet is largely a sustainable diet ${ }^{(6-12)}$. According to the FAO, sustainable diets are those diets with low environmental impacts which contribute to food and nutrition security and to healthy life for present and future generations. Sustainable diets are protective and respectful of biodiversity and ecosystems, culturally acceptable, accessible, economically fair and affordable; nutritionally adequate, safe and healthy; while optimizing natural and human resources, ${ }^{, 13)}$.

Public policy, as well as community and industry actions are required to achieve healthy and sustainable diets (HSD). Although the importance of incorporating environmental sustainability themes into PHN policy reference standards was recognised at least as far back as $1986^{(14)}$, it is relatively recently that calls for policy responses to redesign food systems to promote HSD have gained traction and become a focus for food policy ${ }^{(4,13,15)}$. A significant research investment investigating PHN and environmental sustainability problems is now underway and a substantial amount of evidence is emerging. However, PHN and environmental sustainability problems are classic examples of 'wicked' policy 
problems - they are complex and their causes and solutions are unclear and contested ${ }^{(16)}$. There can be a lack of context to the collected data and uncertainty about their utility for policy making. Also, the substantial amount of evidence being generated and the pace at which it is being accumulated can be overwhelming to policy makers. The intractability of these challenges frequently results in food and nutrition policy activities being politicised and fragmented.

Policy formulation, which is the process of identifying and targeting policy solutions to policy problems ${ }^{(17)}$, is a critical step in strengthening the evidence-policy relationship to promote HSD. Policy formulation research focuses on providing tools to strengthen communication between researchers and policy makers to promote evidence-informed policy making. A policy formulation tool is defined as 'a technique, scheme, device or operation ... which can be used to collect, condense and make sense of different kinds of policy relevant knowledge to perform some or all of the various inter-linked tasks of policy formulation',(18).

The objective of the present research was to develop a policy formulation tool for strategically informing food and nutrition policy activities to promote HSD. The objective was achieved through the development of two complementary components. First, a conceptual framework of the environment-PHN relationship was constructed as a heuristic device to characterise the situation and conceptualise the HSD problem. Second, an 'Orders of Food Systems Change' schema was developed to operationalise the framework by helping identify, assess and prioritise policy options. The implications of the policy formulation tool for food and nutrition policy are discussed.

\section{Method}

The research objective was achieved by adapting Turnpenny and colleagues' 'five key tasks of policy formulation': (i) characterisation of the current situation; (ii) problem conceptualisation; (iii) identification of policy options; (iv) assessment of potential policy options; and (v) proposing a specific policy design ${ }^{(18)}$. A policy formulation tool consisting of two complementary components was developed to address these policy formulation tasks. These components are well suited for helping the tool account for the ideological and contested nature of the policy-making process. First, a conceptual framework was constructed to organise thinking about the complex nature and scope of environmental and PHN problems and their causes (characterising the current situation; problem conceptualisation). Second, an 'orders of change' schema was adapted for a food systems context to analyse the ideological contexts and circumstances associated with the policy setting (identification of policy options; assessment of potential policy options; proposing a specific policy design).

The conceptual framework was developed from a narrative review of the PHN and food systems literature. The
Orders of Food System Change schema was informed by a review of the literature on systems change dynamics and practices, where systems change is understood as an intentional process designed to alter the status quo by shifting and realigning the form and function of a targeted system,(19). The systems change literature covers many dimensions, including where to intervene in a system ${ }^{(20)}$ and the degree of change for a system. In keeping with the identified theoretical insights for policy formulation tools, we adapted to a food systems context McLachlan and Garrett's 'Nutrition Change Strategies'(21) which itself is largely derivative of Pruitt and Waddell's 'Criteria for Distinguishing Orders of Change in Problem Solving Initiatives $^{,(22)}$. These strategies and initiatives organise policy activities around 'first'-, 'second'- or 'third'-order change, distinguished by contrasting ideological perspectives on the type and extent of change needed to 'solve' a policy problem. The schema is intended to be applied to an analysis of the modern industrialised food system. The resulting schema shares common features with Garnett's three perspectives on sustainable food security - (i) efficiency (first-order change); (ii) demand restraint (secondorder change); and (iii) food system transformation (thirdorder change) - that also draw on different ideologies towards what is achievable and what is desirable in addressing this problem ${ }^{(23)}$.

\section{Results}

\section{The conceptual framework of the environment- public bealth nutrition relationship}

The proposed conceptual framework comprises three integrated dimensions:

1. a structure built around a bidirectional relationship mediated via the food system;

2. internal mechanisms that operate through system dynamics; and

3. external interactions that influence the nature and scope of the framework within ecological parameters.

\section{The structure of the framework}

The structural dimension to the conceptual framework is depicted in Fig. 1. The environment and PHN coexist sharing a dynamic bidirectional relationship with the food system $^{(6)}$. In one direction (black arrows), the environment provides the resource supply, in the form of water, energy, soil, nutrients and biodiversity, as well as the climate that together influence the quantity, quality, composition, variety and safety of the food supply. The food supply and its consumption impact on PHN, as measured in terms of the population's nutritional status ${ }^{(24-26)}$. In the other direction (grey arrows), PHN has a modest influence (thinner arrow) on food demand, particularly the type and amount of food selected. Food demand, in turn, has an influence on resource demand in 


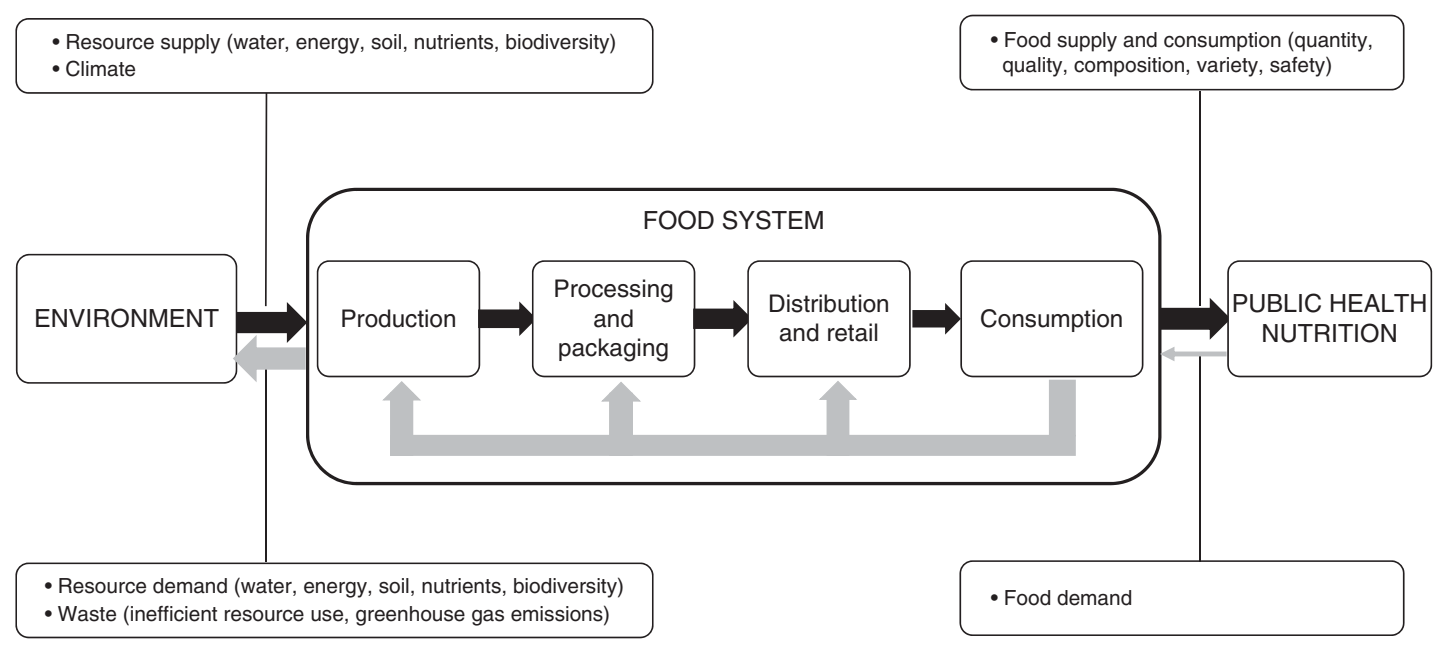

Fig. 1 Conceptual framework of the environment-pubic health nutrition relationship

the form of water, energy, soil, nutrients and biodiversity. Also, when demanded food is not consumed it results in food waste which has an indirect impact on resource demand because it represents an inefficient use of resources, and a direct impact on climate because it is a contributor to greenhouse gas emissions ${ }^{(27)}$. This resource demand and wastage have a negative impact on environmental sustainability ${ }^{(28,29)}$.

In both directions the relationship is mediated via the food system ${ }^{(30,31)}$. The food system incorporates food production, processing and packaging, distribution and retail, and consumption. The application of food systems thinking to strategically plan, develop and evaluate food and nutrition policy was first proposed by Heywood and Lund-Adams ${ }^{(32)}$, who articulated the concept and provided a simple framework consisting of four interlinked subcomponents. Since then, food systems thinking has been advocated for policy action by many researchers ${ }^{(33-36)}$, including those who have explicitly recommended using it to connect environment and PHN problems ${ }^{(30,31,37-39)}$.

\section{The internal mechanisms of the framework}

The internal mechanisms of the conceptual framework are dependent on the operation of the food system through which the environment-PHN relationship is mediated. A system is understood in this context as an interconnected set of elements that is coherently organised in a way that achieves something ${ }^{(40)}$. Systems thinking is used for strategic planning and evaluation in a variety of settings. Its ability to investigate complex policy problems means that it is particularly well suited to the analysis of PHN and environmental sustainability problems through its adaption to a food systems context.

The existence of multiple interrelationships within food systems means that synergies exist between health and environmental intermediates and outcomes. This has two contrasting ramifications. There may arise co-risks if an unstable system is not adjusted. Alternatively, there may be co-benefits if that system is stabilised. For example, shifting from the current Western-style diet to a relatively more plant-based diet is likely not only to be better for public health, but also lessen greenhouse gas emissions ${ }^{(41)}$.

\section{The external interactions of the framework}

The food system does not exist in isolation; instead it interacts with ecological, social, economic and political systems $^{(37)}$. In the context of the environment-PHN relationship it is the external interactions between the food and ecological systems that are especially significant in influencing the nature and scope of the conceptual framework. This influence is exerted through the dynamics of the following three ecological parameters.

1. Physical limits on the food system. The food system operates within finite boundaries ${ }^{(42)}$ dictated by the physical constraints of resource availability and waste management as originally outlined by the Club of Rome's landmark 'Limits to Growth' analysis of ecological systems ${ }^{(43)}$.

The food system's role in mediating the environment-PHN relationship is finely balanced. Historically, although there have been fluctuations in the relationship's stability, the environment has continually provided a food supply sufficient to nurture a critical number of people at least until reproductive age, and food consumption patterns have been compatible with environmental sustainability. Now, assessments are that the relationship is unbalanced and demands are overloading its resource capacity ${ }^{(44)}$.

2. Complex interconnected relationships within the food system. The food system consists of a series of integrated components. The integrity of the system is dependent on functioning interconnected relationships between these components which in turn are determined by the exposure of each relationship component to a range of environmental and behavioural 
inputs and outputs. A fully operational relationship requires the functioning of a high level of multiple complex interrelationships within the system's structure. These interrelationships operate through feedback loops and time delays and are unpredictable ${ }^{(37)}$. A change in one interrelationship can have complex flowon effects impacting on other parts of the system.

An implicit assumption with many analyses is that there are linear responses to changes in one part of a system. Yet, as the likelihood of exceeding ecological thresholds and tipping points increases, the assumptions about linearity implicit in ecologically influenced systems become less certain. The complexity and fragility of systems, and their vulnerability to shocks and destabilising of their basic interrelationships, point to the possibility of non-linear responses and a 'cascade of risks ${ }^{\text {, (45) }}$ rather than incremental adaptive responses.

3. Dynamic nature of the food system. The food system is a constantly evolving and adapting entity. Its resilience enables many changes in inputs and outputs to be accommodated to maintain the integrity of the system. However, if the underpinning ecological principles are disrupted, for example the finite limits are crossed or the internal relationships are unravelled, then it is inevitable that the system's structure and operation will become unstable. The capacity to prevent, reverse or adapt to system degradation depends on the extent and pace of the disruption. An additional consideration with protecting the integrity of the environment-PHN relationship is the need for continuity of supply. Relatively brief shocks that might disrupt the food system for just a few months can be catastrophic as people's nutritional reserves cannot extend beyond several weeks without replenishment. For example, Suweis et al. ${ }^{(46)}$ report that over the past two decades the resilience and stability of food systems have diminished as they have become increasingly susceptible to perturbations in demographic growth and the intensification of international food trade as more countries increase their reliance on food imports.

The interrelationships among the structure, internal mechanisms and external interactions of the conceptual framework (Fig. 1) are many and complex. For example, climate affects the structure and operation of the food system. The climate is changing with increased and unprecedented concentrations of carbon dioxide and ozone in the environment $^{(47)}$ and recent significant temperature rises along with increased and more severe occurrences of extreme weather events ${ }^{(48)}$. These climate change measures can have adverse effects on food yield ${ }^{(49,50)}$, quality ${ }^{(51,52)}$, micronutrient $^{(53)}$ and macronutrient ${ }^{(54)}$ composition, and safety ${ }^{(55)}$. These adverse effects on the food supply can, in turn, affect food security and PHN. Conversely, BMI is a proxy indicator of how PHN can place demands on the food system. Globally, 39\% of adults have a BMI classifying them as overweight or obese ${ }^{(56)}$. Overweight and obesity are proxy indicators of food overconsumption. In many countries, per capita caloric consumption is, on average, about $2092 \mathrm{~kJ} / \mathrm{d}(500 \mathrm{kcal} / \mathrm{d})$ greater than is needed nutritionally ${ }^{(13)}$. This overconsumption, in turn, has an adverse effect on carbon dioxide emissions as consumption of food beyond a person's energy requirements represents an unnecessary demand on the production, processing and distribution of food. This adverse effect on carbon dioxide emissions can, in turn, affect climate change and the environment.

The data from this small number of examples indicate that relationships mediated by the food system are operating outside physical limits and into the future the integrity of the environment-PHN relationship will be increasingly ecologically unsustainable. Food systems are broken. Historically, food systems' structures and operations have been subjected to continual variation in inputs and outputs; the difference in contemporary times is that the extent and pace of variations are destabilising the ecological balance of food systems.

\section{The Orders of Food System Change schema}

The Orders of Food Systems Change schema is presented in Table 1. The schema's columns are organised around three orders of change for redesigning food systems. A first-order change relates to the need to compensate for and/or build resilience to existing HSD problems and that this outcome can be achieved by adjustments to individual components of the food system to improve their performance efficiency. A second-order change is organised around the need to reduce the risk of HSD problems arising and that this outcome can be achieved by reforming interactions among components within the food system. A third-order change relates to the need to promote the food system as a resource for HSD and that this outcome can be achieved by transforming the orientation of the food system as a whole.

The schema's rows specify details of the criteria that characterise the ideological distinctions between the three orders of food system change. These criteria are: (i) how the HSD problem is framed and its cause ascribed to the food system; (ii) the process for change; (iii) participation of stakeholders; and (iv) governance arrangements. An example of a policy approach to bring about food system change is also provided to illustrate each order of change.

\section{Discussion}

Food and nutrition policy activities are essential to redesign the structure and operation of the food system to promote HSD. The two components of the policy formulation tool work together to fulfil Turnpenny et al.'s five tasks necessary to strategically inform food and nutrition policy activities. How the combination of the conceptual framework and schema forms an integrated policy formulation tool to strengthen communication between 
Table 1 The Orders of Food System Change schema

\begin{tabular}{|c|c|c|c|}
\hline Criterion & First-order change (Adjust) & Second-order change (Reform) & Third-order change (Transform) \\
\hline $\begin{array}{l}\text { How the HSD } \\
\text { problem is framed } \\
\text { and its cause } \\
\text { ascribed to the } \\
\text { food system }\end{array}$ & $\begin{array}{l}\text { If a problem exists it is a } \\
\text { consequence of technical } \\
\text { inefficiencies within the system } \\
\text { design }\end{array}$ & $\begin{array}{l}\text { Accepts that there is a problem and its } \\
\text { cause(s) are associated with } \\
\text { structural and operational } \\
\text { shortcomings within the system }\end{array}$ & $\begin{array}{l}\text { Accepts the problem as a real and } \\
\text { present danger and a consequence } \\
\text { of a broken system created from } \\
\text { flawed social, economic and political } \\
\text { values }\end{array}$ \\
\hline Process for change & $\begin{array}{l}\text { Preserves the established power } \\
\text { structure and relationships } \\
\text { among actors in the system }\end{array}$ & $\begin{array}{l}\text { Challenges established power } \\
\text { relationships shaping components } \\
\text { within the system; promotes } \\
\text { opportunities for interactions among } \\
\text { a diverse range of actors in the } \\
\text { system }\end{array}$ & $\begin{array}{l}\text { Promotes change in relationships } \\
\text { towards whole-system awareness } \\
\text { and identity; promotes examination } \\
\text { of the deep structures that sustain } \\
\text { the system }\end{array}$ \\
\hline $\begin{array}{r}\text { Participation of } \\
\text { stakeholders }\end{array}$ & $\begin{array}{l}\text { Replicates the established } \\
\text { decision-making group and } \\
\text { power relationships. Tends to } \\
\text { be global in scope }\end{array}$ & $\begin{array}{l}\text { Brings relevant actors (government, } \\
\text { civil society, academics and } \\
\text { practitioners, producers, food } \\
\text { industry) into the problem-solving } \\
\text { conversation in ways that enable } \\
\text { them to influence the decision- } \\
\text { making process }\end{array}$ & $\begin{array}{l}\text { Promotes social inclusion, empowered } \\
\text { producers and citizens actively } \\
\text { engaged with the food system } \\
\text { instead of being passive takers. } \\
\text { Tends to be local in scope }\end{array}$ \\
\hline $\begin{array}{l}\text { Governance } \\
\text { arrangements }\end{array}$ & $\begin{array}{l}\text { Projects within individual } \\
\text { departments }\end{array}$ & $\begin{array}{l}\text { Programmes across departments } \\
\quad \text { (usually led by health department) }\end{array}$ & $\begin{array}{l}\text { Programmes integrating all relevant } \\
\text { departments (whole-of-government } \\
\text { approach) }\end{array}$ \\
\hline $\begin{array}{l}\text { Example of the policy } \\
\text { approach to bring } \\
\text { about food system } \\
\text { change }\end{array}$ & $\begin{array}{l}\text { Applies technological innovations } \\
\text { to improve the resilience and/or } \\
\text { adaptive capacity of } \\
\text { components of the food system }\end{array}$ & $\begin{array}{l}\text { Applies a mechanistic analysis to } \\
\text { identify leverage points within the } \\
\text { system (different levels of } \\
\text { government and/or sectors with } \\
\text { responsibilities for system } \\
\text { components) to reform their structure } \\
\text { and operation }\end{array}$ & $\begin{array}{l}\text { Applies a systems-level analysis to } \\
\text { identify the system's purpose and } \\
\text { power relationships to reorientate its } \\
\text { function from being predominantly a } \\
\text { component of the industrialised } \\
\text { economy to a health, social, } \\
\text { environmental and economic } \\
\text { resource }\end{array}$ \\
\hline
\end{tabular}

HSD, healthy and sustainable diet.

researchers and policy makers to promote evidenceinformed policy making is discussed below.

The conceptual framework is normative, proposing that there are structural, internal and external dynamics in the characterisation of the nature and scope of the environment-PHN relationship and conceptualising HSD problems. Structurally, the framework's mapping of the food system within the environment-PHN relationship provides a point of reference to identify sectors and levels of governance that impact on the structure and operation of the food system. ${ }^{(57)}$ It affirms the notion of identifying leverage points or strategic places to intervene within a system $^{(20,58)}$. The framework highlights the need to recognise the nexus between food supply and food demand impacts on the operation of the food system and therefore the need for food policy activities to address these supply and demand components in a synchronised manner ${ }^{(59)}$. As Capone et al. comment, 'Changes in both food consumption and food production are important to ensure more sustainable food systems and to achieve food and nutrition security. ... Moving towards healthy and sustainable food consumption and production means addressing systemically the consumptive demand as well as productive supply'(60). For example, a government health department might not only set a policy to promote healthy and sustainable food procurement practices in health-care settings ${ }^{(61)}$ but also work to synchronise this policy activity with nutrition education activities to foster demand for healthy food in these same settings.

The framework's internal mechanisms in terms of food systems thinking encourages policy practitioners to extend their analysis and framing of policy problems and solutions from immediate to distal causes and consequences. As Malhi et al. observe, "When tackling a complex problem, the tendency is to oversimplify the problem and the causal linkages or pathways that give rise to outcomes of interest. But for systems where variables have many inputs and outputs, and multiple interacting components create both balancing and reinforcing feedback loops, the outcomes of interest emerge from the system as a whole,(38).

The external interactions of the framework highlight that policy to change the food system can have flow-on effects to the ecological, political, economic and social systems and vice versa. For example, change in the food system that leads to food insecurity can result in civil unrest and affect the stability of the political system. Conversely, change in the political system may lead to civil unrest and result in food system instability and this can affect food security. These external interactions can become self-perpetuating.

The schema is the necessary complement to operationalise the conceptualisation of HSD problems by helping identify, assess and propose policy options. It is necessary because as the insights from the brief review of 
policy science theories highlighted, policy making is a political process. For example, the rapid assessment of just two sequences of linear relationships within the conceptual framework provided evidence that the integrity of the environment-PHN relationship is at risk, but there are contrasting ideological views on the cause of this risk and the preferred policy response. The schema's three orders of change help to understand the characteristics of these ideological views and account for political realities in formulating policy activities.

Generally, interventions consistent with first-order changes that modestly adjust existing food systems to address specific problems are relatively uncontroversial and usually able to be decided upon and implemented more rapidly than interventions aligned with second- and third-order changes. Yet, many food policy researchers believe that framing HSD problems as isolated events and tackling with modest system adjustments misrepresents the complex multiple interactions within the environmentPHN relationship and promotes fragmented attempts to fix a complex problem. They often argue that the magnitude of the problem is sufficiently substantial and the need for a policy response so urgent, that second- or third-order food system changes are required to mitigate the cause of the problem and find a solution. For example, in relation to second-order change, Reisch et al. call for food system reforms by acting on the drivers of food production and consumption using integrative, cross-sectoral and population-wide policies ${ }^{(62)}$. An example of third-order change thinking is contained in the International Panel of Experts on Sustainable Food Systems' paper, 'The New Science of Sustainable Food Systems, ${ }^{,(63)}$ and in particular its analysis of the role of power imbalances in determining the way food systems operate. This analysis resonates with that of others calling for third-order change: for example, promoting the notions of 'food democracy', which Lang describes as 'the demand for greater access and collective benefit from the food system ${ }^{,(64)}$, and food sovereignty ${ }^{(39)}$ through which local food producers and citizens are empowered to actively engage with the food system.

The reality is that strategically we may need a combination of all three orders of change. As Garnett has argued, there is a need to reorientate policy thinking away from pitting one order of change over another, to a situation in which insights from all three orders of change are considered in a coherent and nuanced approach ${ }^{(28)}$. The balance among these different orders will vary with contexts, political feasibility, and economic and social circumstances in different regions of the world ${ }^{(65)}$. Unexpected shocks to the current system, furthermore, may result in rapid attitude shifts and lead to broad support for higher orders of change. For example, if a major disruption was to occur there may need to be greater investment in adaptive technological strategies such as novel food fortification interventions to protect food and nutrition security ${ }^{(66)}$.
These contingencies indicate a range of policies from different orders of change are likely to be required at different points and in different contexts in seeking to redesign the food system to promote HSD. In the context of addressing food insecurity and poor nutrition Friel and Ford argue for policy that targets the systemic causes of these problems. This approach, which equally applies to shifting to a HSD, 'has implications for economic, agriculture, food, social and health policy at the global, regional, national and local levels ${ }^{(67)}$. In their analysis of policy options to tackle food and nutrition security, Qureshi et al. conclude that the effectiveness of such policies is determined by selecting the best 'bundle' of policy instruments (targeted at demand, access and supply) for the specific context and country to achieve goals and avoid perverse outcomes ${ }^{(68)}$.

\section{Strengths and limitations of the policy formulation tool}

The policy formulation tool is novel, innovative, practical, problem-solving oriented and theory-driven. Its two individual components have their own inherent strengths. The conceptual framework extends the thinking presented in other food systems frameworks by locating the food system as the mediating variable within the bidirectional relationship between the environment and PHN. The schema helps account for political realities in policy making with its premise that the choice of which orders of change is less about evidence and more about reflecting the inevitable presence of ideology in decision making about the structure and operation of the food system. It is the combination of the framework's organisation of the structure and operation of the food system and the schema's capturing of ideological-based views that provides the high-level analysis necessary for the policy formulation tool to strategically inform policies to promote HSD.

The substantial size and complexity of the environment-PHN relationship and its multiple components and interrelationships mean that inevitably there may be limitations with the conceptual framework. The food system portrayed in Fig. 1 was a generic representation and cannot be expected to depict the diversity of interconnected local, national and regional food systems that vary in size, structure and operation. In addition, the need to simplify the dynamic nature of the food system meant that it was presented in isolation rather than interacting with many social, economic and political systems.

The orders of change framework has potential limitations. For example, there may be challenges in classifying some activities between categories. As Garnett comments, 'these perspectives are not rigid and mutually exclusive. There will often be overlap between them and they are perhaps better viewed as ideological "tendencies" rather than closed belief systems,'(23). 


\section{Conclusion}

The 21st century food-related population health and environmental challenges are unprecedented in their nature, scope and scale. The conceptual framework helps orientate the multiple interconnected causes and consequences of environmental and PHN problems and these challenges. The schema helps account for political realities in policy making and is a key link to operationalise the framework's concepts to policy actions aimed at redesigning food systems. In combination they provide a policy formulation tool for strategically informing food and nutrition policy activities to redesign food systems and promote HSD.

\section{Acknowledgements}

Acknowledgements: The authors would like to thank Julie Woods for her comments on earlier drafts of the paper. Financial support: This research received support from the Australian Research Council Linkage Project entitled 'Modelling policy interventions to protect Australia's food security in the face of environmental sustainability challenges' (LP120100168). The funder had no role in the design, analysis or writing of this article. Conflict of interest: None. Authorship: M.A.L. led the conception and design of the research, the review and interpretation of the literature, and the drafting of the article; S.F., K.W., S.W.J. and S.C. contributed to the literature review and analysis, and the drafting of the article. Ethics of buman subject participation: Not applicable.

\section{References}

1. Food and Agriculture Organization of the United Nations, World Food Programme \& International Fund for Agricultural Development (2012) The State of Food Insecurity in the World 2012. Economic Growth is Necessary But Not Sufficient to Accelerate Reduction of Hunger and Malnutrition. Rome: FAO.

2. Lim SS, Vos T, Flaxman AD et al. (2012) A comparative risk assessment of burden of disease and injury attributable to 67 risk factors and risk factor clusters in 21 regions, 1990-2010: a systematic analysis for the Global Burden of Disease Study 2010. Lancet 380, 2224-2260.

3. Searchinger T, Hanson C, Ranganathan J et al. (2013) The Great Balancing Act, Working Paper, Installment 1 of Creating a Sustainable Food Future. Washington, DC: World Resources Institute.

4. Intergovernmental Panel on Climate Change (2014) Food security and food production systems. In Climate Change 2014: Impacts, Adaptation, and Vulnerability. Part A. Global and Sectoral Aspects. Contribution of Working Group II to the Fifth Assessment Report of the Intergovernmental Panel on Climate Change, pp. 485-534 [CB Field, VR Barros, DJ Dokken et al., editors]. Cambridge: Cambridge University Press.

5. Food and Agriculture Organization of the United Nations (2013) The State of Food and Agriculture: Food Systems for Better Nutrition. Rome: FAO.

6. Friel S, Barosh JL \& Lawrence M (2014) Towards healthy and sustainable food consumption: an Australian case study. Public Health Nutr 17, 1156-1166.
7. Macdiarmid JI, Kyle J, Horgan JW et al. (2012) Sustainable diets for the future: can we contribute to reducing greenhouse gas emissions by eating a healthy diet? Am J Clin Nutr 96, 632-639.

8. Mozner ZV \& Csutora M (2013) Designing lifestyle-specific food policies based on nutritional requirements and ecological footprints. Sustain Sci Pract Policy 9, 48-59.

9. Saxe H (2014) The New Nordic Diet is an effective tool in environmental protection: it reduces the associated socioeconomic cost of diets. Am J Clin Nutr 99, 1117-1125.

10. Tilman D \& Clark M (2014) Global diets link environmental sustainability and human health. Nature 515, 518-522.

11. Bajželj B, Benton TG, Clark M et al. (2015) Synergies between healthy and sustainable diets. UN Global Sustainable Development Report (GSDR) Brief. https://sustaina bledevelopment.un.org/content/documents/635987-Baj zelj-Synergies\%20between $\% 20$ healthy $\% 20$ and $\% 20$ sustain able\%20diets.pdf (accessed July 2015).

12. Milner J, Green R, Dangour AD et al. (2015) Health effects of adopting low greenhouse gas emission diets in the UK. BMJ Open 5, e007364.

13. Food and Agriculture Organization of the United Nations (2012) Sustainable Diets and Biodiversity: Directions and Solutions for Policy, Research and Action. Rome: FAO.

14. Gussow J \& Clancy K (1986) Dietary guidelines for sustainability. J Nutr Educ 18, 1-5.

15. Lang T \& Barling D (2013) Nutrition and sustainability: an emerging food policy discourse. Proc Nutr Soc 72, 1-12.

16. Hamm MW (2009) Principles for framing a healthy food system. J Hunger Environ Nutr 4, 241-250.

17. Howlett M (2011) Designing Public Policies: Principles and Instruments. Abingdon: Routledge.

18. Turnpenny JR, Jordan AJ, Benson D et al. (2015) The tools of policy formulation: an introduction. In The Tools of Policy Formulation: Actors, Capacities, Venues and Effects, pp. 3-29 [AJ Jordan and JR Turnpenny, editors]. Cheltenham: Edward Elgar Publishing.

19. Foster-Fishman P, Nowell B \& Yang H (2007) Putting the system back into systems change: a framework for understanding and changing organizational and community systems. Am J Community Psychol 39, 197-215.

20. Meadows D (1999) Leverage Points: Places to Intervene in a System. Hartland, VT: The Sustainability Institute.

21. McLachlan M \& Garrett J (2008) Nutrition change strategies: the new frontier. Public Health Nutr 11, 1063-1075.

22. Pruitt B \& Waddell S (2005) Dialogic Approaches to Global Challenges: Moving From 'Dialogue Fatigue' to Dialogic Change Processes. Working Paper prepared for the Generative Dialogue Project. http://www.democraticdialogue network.org/app/documents/view/en/1124 (accessed August 2015).

23. Garnett T (2014) Three perspectives on sustainable food security: efficiency, demand restraint, food system transformation. What role for LCA? J Cleaner Prod 73, 10-18.

24. Tait PW, McMichael AJ \& Hanna EG (2014) Determinants of health: the contribution of the natural environment. Aust N Z J Public Health 38, 104-107.

25. Ericksen PJ, Ingram JSI \& Liverman DM (2009) Food security and global environmental change: emerging challenges. Environ Sci Policy 12, 373-377.

26. Edwards F, Dixon J, Friel S et al. (2011) Climate change adaptation at the intersection of food and health. Asia PacJ Public Health 23, Suppl. 2, 91S-104S.

27. Vermeulen SJ, Campbell BM \& Ingram JSI (2012) Climate change and food systems. Annu Rev Environ Res 37, 195-222.

28. Garnett T (2013) Food sustainability: problems, perspectives and solutions. Proc Nutr Soc 72, 29-39.

29. Moomaw W, Griffin T, Kurczac K et al. (2012) The Critical Role of Global Food Consumption Patterns in Achieving Sustainable Food Systems and Food for All, A UNEP 
Discussion Paper. Paris: United Nations Environment Programme, Division of Technology, Industry and Economics.

30. Lang T (2009) Reshaping the food system for ecological public health. J Hunger Environ Nutr 4, 315-335.

31. Kickbusch I (2010) The Food System: A Prism of Present and Future Challenges for Health Promotion and Sustainable Development. Bern: Health Promotion Switzerland.

32. Heywood P \& Lund-Adams M (1991) The Australian food and nutrition system: a basis for policy formulation and analysis. Aust J Public Health 15, 258-270.

33. Sobal J, Khan L \& Bisogni C (1998) A conceptual model of the food and nutrition system. Soc Sci Med 47, 853-863.

34. Ericksen PJ (2008) Conceptualizing food systems for global environmental change research. Glob Environ Change 18, 234-245.

35. Ingram J (2011) A food systems approach to researching food security and its interactions with global environmental change. Food Sec 3, 417-431.

36. Rutten LF, Yaroch AL \& Story M (2011) Food systems and food security: a conceptual model for identifying food system deficiencies. J Hunger Environ Nutr 6, 239-246.

37. Hammond RA \& Dubé L (2012) A systems science perspective and transdisciplinary models for food and nutrition security. Proc Natl Acad Sci U S A 109, 12356-12363.

38. Malhi L, Karanfil O, Merth T et al. (2009) Places to intervene to make complex food systems more healthy, green, fair, and affordable. J Hunger Environ Nutr 4, 466-476.

39. Burlingame B (2014) Grand challenges in nutrition and environmental sustainability. Front Nutr 1, 1-2.

40. Meadows D (2008) Thinking in Systems: A Primer. White River Junction, VT: Chelsea Green Publishing Company

41. Friel S, Dangour AD, Garnett T et al. (2009) Public health benefits of strategies to reduce greenhouse-gas emissions: food and agriculture. Lancet 374, 2016-2025.

42. Rockstrom J, Steffen W, Noone K et al. (2009) Planetary boundaries: exploring the safe operating space for humanity. Ecol Soc 14, 1-33.

43. Meadows DH, Meadows DL, Randers J et al. (1972) The Limits to Growth. New York: Universe.

44. McMichael A (1994) Planetary Overload: Global Environmental Change and the Health of the Human Species. Cambridge: Cambridge University Press.

45. The World Bank (2012) Turn Down the Heat: Why $a 4^{\circ} \mathrm{C}$ Warmer World Must Be Avoided. A Report for the World Bank by the Potsdam Institute for Climate Impact Research and Climate Analytics. Washington, DC: World Bank.

46. Suweis S, Carr JA, Maritan A et al. (2015) Resilience and reactivity of global food security. Proc Natl Acad Sci U S A 112, 6902-6907.

47. Intergovernmental Panel on Climate Change (2014) Summary for policymakers. In Climate Change 2014: Impacts, Adaptation, and Vulnerability. Part A: Global and Sectoral Aspects. Contribution of Working Group II to the Fifth Assessment Report of the Intergovernmental Panel on Climate Change, pp. 1-34 [CB Field, VR Barros, DJ Dokken et al. editors]. Cambridge: Cambridge University Press.

48. World Meterological Organization (2015) WMO Statement on the Status of the Global Climate in 2014. Geneva: WMO.

49. Challinor AJ, Watson J, Lobell DB et al. (2014) A metaanalysis of crop yield under climate change and adaptation. Nat Clim Change 4, 287-291.
50. Ray DK, Gerber JS, MacDonald GK et al. (2015) Climate variation explains a third of global crop yield variability. Nat Commun 6, 5989.

51. Chakraborty S \& Newton AC (2011) Climate change, plant diseases and food security: an overview. Plant Pathol 60, 2-14.

52. Battisti DS \& Naylor RL (2009) Historical warnings of future food insecurity with unprecedented seasonal heat. Science 323, 240-244

53. Myers SS, Zanobetti A, Kloog I et al. (2014) Increasing $\mathrm{CO}_{2}$ threatens human nutrition. Nature 510, 139-142.

54. Bloom AJ, Burger M, Kimball BA et al. (2015) Nitrate assimilation is inhibited by elevated $\mathrm{CO}_{2}$ in field-grown wheat. Nat Clim Change 4, 477-480.

55. Tirado MC, Clarke R, Jaykus LA et al. (2010) Climate change and food safety: a review. Food Res Int 43, 1745-1765.

56. World Health Organization (n.d.) Global Health Observatory (GHO) Data. Overweight and Obesity, Adults Aged 18+. http://www.who.int/gho/ncd/risk_factors/ overweight_text/en/ (accessed July 2015).

57. Sacks G, Swinburn B \& Lawrence M (2008) A systematic policy approach to changing the food system and physical activity environments to prevent obesity. Aust $N Z$ Health Policy 5, 13.

58. West PC, Gerber JS, Engstrom PM et al. (2014) Leverage points for improving global food security and the environment. Science 345, 325-328.

59. Bajzelj B, Richards KS, Allwood JM et al. (2014) Importance of food-demand management for climate mitigation. Nat Clim Change 4, 924-929.

60. Capone R, El Bilali H, Debs P et al. (2014) Food system sustainability and food security: connecting the dots. J Food $\operatorname{Sec} \mathbf{2}, 13-22$.

61. Harvie J, Mikkelsen L \& Shak L (2009) A new health care prevention agenda: sustainable food procurement and agricultural policy. J Hunger Environ Nutr 4, 409-429.

62. Reisch L, Eberle U \& Lorek S (2013) Sustainable food consumption: an overview of contemporary issues and policies. Sustain Sci Pract Policy 9, 7-25.

63. International Panel of Experts on Sustainable Food Systems (2015) The New Science of Sustainable Food Systems: Overcoming Barriers to Food Systems Reform. http://www.ipes-food.org/images/Reports/IPES_report01_ 1505_web_br_pages.pdf (accessed July 2015).

64. Lang T (1999) Food policy for the 21st century: can it be both radical and reasonable? In For Hunger-Proof Cities: Sustainable Urban Food Systems, pp. 216-224 [M Koc, R MacRae, LJA Mougeot et al., editors]. Ottawa: The International Development Research Centre.

65. Albrecht C, Johnson R, Hamann S et al. (2013) Toward alternative food systems development: exploring limitations and research opportunities. J Agric Food Syst Community Dev 3, 151-159.

66. Millward D \& Garnett T (2010) Plenary Lecture 3: Food and the planet: nutritional dilemmas of greenhouse gas emission reductions through reduced intakes of meat and dairy foods. Proc Nutr Soc 69, 103-118.

67. Friel S \& Ford L (2015) Systems, food security and human health. Food $\operatorname{Sec}$ 7, 437-451.

68. Qureshi ME, Dixon J \& Wood M (2015) Public policies for improving food and nutrition security at different scales. Food Sec 7, 393-403. 